\title{
APPLICATION OF REMOTE SENSING AND GOOGLE EARTH ENGINE FOR MONITORING ENVIRONMENTAL DEGRADATION IN THE NILGIRI BIOSPHERE RESERVE AND ITS ECOSYSTEM OF WESTERN GHATS, INDIA
}

\author{
Abdul Rahaman. S*, Venkatesh. R, \\ Department of Geography, Bharathidasan University, Tiruchirappalli, Tamil Nadu, India. \\ abdulatgeo@gmail.com, venkatvejef007@gmail.com
}

\section{Commission III, WG 10}

\begin{abstract}
KEY WORDS: Environmental Degradation, Google Earth Engine, Nilgiri Biosphere Reserve, Entropy, Support Vector Machine, and Random Forest Classifier
\end{abstract}

\begin{abstract}
:
Biosphere Reserves are archetypal parts of natural and cultural landscapes encompassing over large area of different ecosystem, it represents bio-geographic zones of an region. Globally, the areas of biosphere reserve is shrinking and exploiting due to the extreme climatic condition, natural calamities and anthropogenic activities, which leads to environmental and land degradation. In this paper Nilgiri Biosphere Reserve (NBSR) area has been selected and it represents a biodiversity-rich ecosystem in the Western Ghats and includes two of the ten biogeographical provinces of India. Amongst the most insubstantial ecosystems in the world, the Nilgiri Biosphere Reserve is bearing the substance of climate change evident in increasingly unpredictable rainfall and higher temperatures during recent years. The region was mostly unscathed till two centuries ago, but has witnessed large-scale destruction ever since. In this scenario, a need of application of remote sensing and advance machine learning techniques to monitor environmental degradation and its ecosystem in NBSR is more essential. The objective of the present study is to develop satellite image classification techniques that can reliably to map forest cover and land use, and provide the basis for long-term monitoring. Advanced image classification techniques on the cloud-based platform Google Earth Engine (GEE) for mapping vegetation and land use types, and analyse their spatial distributions. To restore degraded ecosystems to their natural conditions through proper management and conservation practices. In order to understand the nature of environmental degradation and its ecosystem in Nilgiri Biosphere Reserve; following thematic criteria's were grouped in to four major indicators such as Terrain Indicator (TI), Environmental Indicator (EI), Hydro-Meteorological Indicator (HMI) and Socio-Economic Indicator (SEI). The utilisation of remote sensing product of huge datasets and various data product in analysis and advanced machine learning algorithm through Google earth engine are indispensable. After extraction of all the thematic layers by using multi criteria decision and fuzzy linear member based weight and ranks were assigned and overlay in GIS environment at a common pixel size of $30 \mathrm{~m}$. Based on the analysis the resultant layer has been classified into five environmental degraded classes i.e., very high, high, moderate, slight and no degradation. This study is help to identify the degradation and long term monitoring and suggest the appropriate conservation, management and policies, it is a time to implement and protect the Nilgiri biosphere reserves without hindering present stage of natural environment in a sustainable manner.
\end{abstract}

\section{ASSESSMENT OF ENVIRONMENTAL DEGRADATION}

\subsection{Introduction}

Ecosystem is a biological community of all living creatures in province of biosphere. When the normal cycle of ecosystem is interrupts, the living communities and its associate environment starts degrading. The anthropogenic pressure is the key threatening source in degradation of environment (Hadeel et al., 2011). Environmental degradation is a lessening of growing capability of floras as well as disturbing a routine equilibrium state of ecosystem. Globally, developing countries includes India, facing major issues on environmental degradation (Feoli et al., 2002; Hassan et al., 2015) due to massive population and over exploitation. The soil erosion, deforestation, land mining, surface and sub-surface water depletion, landfills, anthropogenic activities and several natural causes are triggering factors for the degradation (Hassan et al., 2015). An environmental degradation persists for long time, which results in many problems are arising like impact of loss of biodiversity, migration, local climatic variations and human health. In the similar way, Nilgiris biosphere is under acute condition in depletion of resources and disruption in ecosystem cycle. The region is a biodiversity-rich ecosystem, in recent times the mining and exploitation of forest resources are highly dominated in the region. The sholas and grasslands play a very important role in retaining water resources. A drastic decline in the sholas and grasslands is one of the reasons for the recent water scarcity in the Nilgiri Biosphere Reserve. This seeks the essential need of monitoring the environmental degradation in Nilgiri biosphere. In the essence of sustainable goal on conserving natural resources, there should be monitoring of qualitative and quantitative aspect of environmental degradation (Wang et al., 2008; Sahoo et al., 2016). Research efforts to reliably mapping and monitor the changing land condition and degradation via land surface and vegetation changes remain a major and open challenge (Vogt et al., 2011). From the year of 1960's the environmental analysis is began (Wang et al., 2008), on those time the assessment framework is quite difficult, later the advancement of Remote Sensing (RS) and Geographic Information System (GIS) technologies (Store and Jokima"ki, 2003; MacMillan et al., 2004), there are many methods are accessible to monitor the environmental issues like ecological impact assessment (Guebas, 2002; Rigina, 2002), landscape monitoring (Gustafson et al., 2005), eco-environmental vulnerability (Nguyen et al., 2016; Liou et al., 2017; Nitheshnirmal et al., 2018) and so on. Since, availability of huge and larger datasets and its processing is very complex in the field of geospatial science. Google Earth Engine is one of the cloud based computation for solving larger and huge volume of data towards spatial problem. GEE is open source 
platform to explore and create multiple analyses by using various datasets. The main advantages of GEE remains the ease-of-use and the consolidated library of global remotely sensed data (Nanki Sidhu, 2018).

In the process of examining the intensity of degradation in study area, there were numerous influencing factors which are arranged in four major indicators such as Terrain Indicator (TI), Environmental Indicator (EI), Hydro-Meteorological Indicator (HMI), and Socio-Economic Indicator (SI). Each major indicator contains its sub-indicators to finalize a result. Those were twelve sub-indicators are obtained and analysed through essential datasets. In order to monitor the environment degradation in the study area, primarily to recognize the present condition on depletion and to assess the degree of vulnerability. Here the advance technique on machine learning algorithm of Support Vector Machine (SVM) (Singh et al., 2014; Shaharum et al., 2018; Krishna et al., 2018) is applied to extract a land use classification and the remote sensing indices are calculated on Random Forest Classifiers through cloud computing technology of Google Earth Engine (GEE) (Johansen et al., 2015; Teluguntla et al., 2018; Zurqani et al., 2018; Tian et al., 2019). All the selected criteria's are extracted using appropriate algorithms and technique in GEE platform in order to bring together them in four main indicators. There are various Multi Criteria Decision Making (MCDM) methods are used in the geospatial studies such as Weighted Product Sum, Entropy, Analytical Hierarchy Process (AHP), Fuzzy Analytical Hierarchical Process (FAHP), Complex Proportional Assessment (COPRAS), Technique for order preference by similarity to the ideal solution (TOPSIS), and fuzzy linear member (Adriaenssens et al., 2004; Li et al., 2009; Rahaman et al., 2015). These are used to calculate the weights and ranks for the criterions to take a decision on alternatives.

In this paper, the datasets utilised in the analysis are Landsat images 8 Optical Land Imagery (OLI) (Othman et al., 2014; Jiang et al., 2018; Choudhary et al., 2018; Zhao et al., 2018) for calculating of remote sensing indices. Shuttle Radar Topography Mission (SRTM) 1 Arc-Second Global Digital elevation to extract an terrain characteristics. Climate Hazards Group InfraRed Precipitation with Station data (CHIRPS) for precipitation and it useful for environmental monitoring (Funk, C, 2015). Ancillary data of Census and road network (BalaSundareshwaran et al., 2019). The aim of the study is to monitor the prevailing condition of environmental degradation to acquire an information on degree of vulnerability to adopt a sustainable management activity and to set a long-term monitoring system. The objective of the present study is to utilisation of cloud based platform of Google Earth Engine for a larger dataset in environmental monitoring. To compute, all the selected input parameters in GEE platform with appropriate rationing and algorithms. The weightages and score for the selected criteria's are assessed through MCDM techniques i.e. Entropy and Complex Proportional Assessment (COPRAS) methods. Integration of four major indicators are (Terrain, Hydro-Metrological, Environmental and Socio-Economic), to assess the status of environmental degradation. To validate the changes from generated result with Google earth image. Suggest appropriate conservation and management strategies for a sustainable environment.

\section{STUDY AREA}

\subsection{Geographical Background}

The Nilgiri Biosphere Reserve (NBSR) was the first biosphere reserve in India established in the year 1986. Wide ranges of ecosystems and provides an ideal habitat for supporting a high degree of endemic flora and fauna. Thus, it was a natural choice for the foremost biosphere reserve of the country. The total geographic area of present study region is $7605 \mathrm{~km}^{2}$ of which NBSR is occupied an area of $5,520 \mathrm{~km}^{2}$. It encompasses parts of three state boundaries i.e. Tamil Nadu (2537.6 km²), Kerala $\left(1455.4 \mathrm{~km}^{2}\right)$ and Karnataka $\left(1527.4 \mathrm{~km}^{2}\right)$. The geographical locational is $76^{\circ}$ to $77^{\circ} 15^{\prime} \mathrm{E}$ and $11^{\circ} 15^{\prime}$ to $12^{\circ} 15^{\prime} \mathrm{N}$ and stretching from Western Ghats (Figure 1). It is a UNESCO World Heritage Site and a global biodiversity hotspot, which is defined by its evergreen shola forests and montane grasslands. NBSR fall under biogeographic regions of Malabar rain forest. The Wyanaad Wildlife Sanctuary, Nagarhole National Park Mudumalai Wildlife Sanctuary, Bandipur National Park, Mukurthi National Park and Silent Valley are the protected areas present within this reserve, along with multi-use landscape where farming, grazing, tourism, and other human activities persists. Nilgiri Biosphere Reserve regions are demarcated into three inter - related zones: Core Zone, Buffer Zone, and Transition Zone. The core area(s) comprises a strictly protectable biodiversity to conservation of ecosystems, landscapes, species and genetic distinction. The buffer zone are adjoins or surrounds core zone, uses and activities are managed in this area in the ways that help in protection of core zone in its natural condition. The transition area is the outermost part of a biosphere reserve, includes settlements, crop lands, managed forests and area for intensive reformation and other economic uses physiognomies of the region.

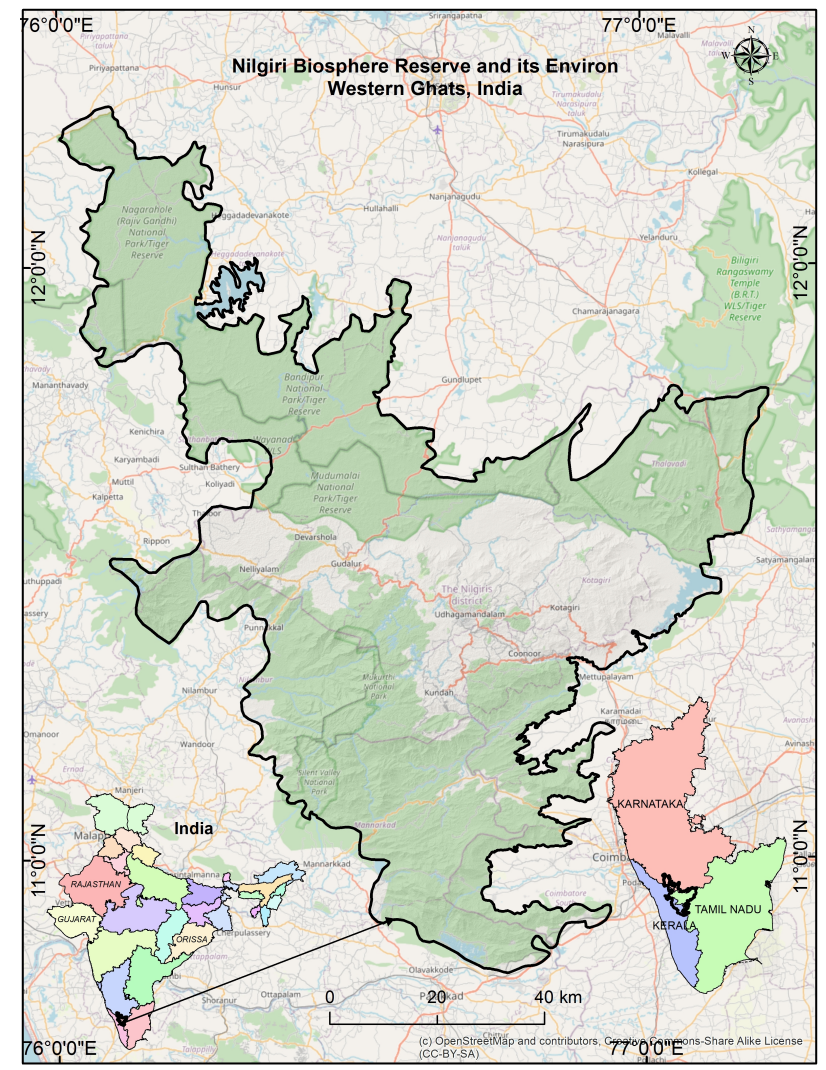

Figure 1. Study Area: Nilgiri Biosphere Reserve 
NBSR and its surrounding area is one of the complex catchment systems in the Peninsular India. Varies major tributaries of Cauvery river such as Moyar, Bhavani, Kabani, Chaliyar etc., and it has 5 major reservoirs / Dam namely Bhavanisagar, Kabni, Paikara, Pillu and Emarald; which are serves for hydroelectric power generation and irrigation for agriculture activity. The annual average rainfall of the region is from 500 $\mathrm{mm}$ to more than $3000 \mathrm{~mm}$; the peak rainfall during both the NE and SW monsoon seasons (June to August). Temperature ranging from $<2{ }^{\circ} \mathrm{C}$ to $41^{\circ} \mathrm{C}$; winter seasons is relatively cooler than other seasons. NBSR consists of substantial natural vegetation system ranging from evergreen forest to dry scrubs, consequently it contrabass to richness of biodiversity.

\section{DATA AND METHODOLOGY}

\subsection{Data}

In order to assess the environmental degradation in the NBSR region; multiple criteria's are grouped under four indicators (TI, HMI, EI, and SEI). Those criteria's are extracted from various datasets, which are processed through GEE platform. Terrain indicator includes the sub factors of elevation, slope, aspect are extracted from Shuttle Radar Topography Mission (SRTM) 1 Arc-Second Global DEM, has a spatial resolution of $30 \mathrm{~m}$. Environmental Indicators are generated by using Multi-seasonal composite Landsat images 8 (OLI) spatial resolution of $30 \mathrm{~m}$ (2019), it has several indices are commonly used to identify vegetation changes (Normalized Difference Vegetation Index (NDVI) and Enhanced Vegetation Index (EVI). For water, Normalized Difference Water Index (NDWI), built up and bare land areas from Normalized Difference Built-up Index (NDBI); and Landuse. The sub factors of HMI are precipitation and land Surface Temperature (LST), of which annual and monthly precipitation data (2019) collected from CHIRPS V2 satellite gridded data, developed by the Climate Hazards Group at the resolution of 0.05 arc degrees. By using Global gridded population 2020 (CIESIN, GPWv411) used to calculate Population density. Global Roads Open Access Data Set, Version 1 (gROADSv1) dataset published by (CIESIN, 2013) used to calculate road network proximity of socio-economic indicators.

The present study utilized range of advanced machine learning image classification methods to map vegetation type and its land use, such as support vector machine (SVM), decision tree, and random forest classifiers through cloud computing technology as Google Earth Engine (GEE). It is a cloud based platform for geospatial analysis as open access. Earth Engine provides a massive imagery data collection, also provides various pixel-based supervised and unsupervised classifiers, including machine learning type algorithms, for mapping implementation. After extraction of all the thematic layers by using multi criteria decision and fuzzy linear member based weight and ranks were assigned and overlay in GIS environment at a common pixel size of $30 \mathrm{~m}$. Based on the analysis the resultant layer has been classified into five environmental degraded classes i.e., Very High Degradation (VHD), High Degradation (VD), Moderate Degradation (MD), Slight Degradation (SD) and No degradation (ND).

\subsection{Methodology}

All the four indicators were processed and classified by using Google Earth Engine with different datasets, numerous algorithms and band rationing techniques (Appendix 2).
3.2.1 Data Process in GEE: GEE is a platform for processing global-scale satellite imagery dating back up to 40 years (Google Earth Engine, 2012). It allows users to utilise global satellite imagery, as well as allowing them to execute complex calculations on the same. Present study, Google Earth Engine Playground (GEEP) application (https://code.earthengine.google.com/), JavaScript API can be used to load specific study region and visualize large satellite imagery and to conduct complex geospatial processes for the selected data. Following data products are used to prepare thematic layers i.e. LANDSAT/LC08/C01/T1, CIESIN/GPWv411, and CHIRPS/PENTAD. Successfully completion of any processed outputs generated within GEE may be exported to other environments (e.g. R, ArcGIS, QGIS) for further analysis (Nanki Sidhu, 2018).

3.2.2 NDVI: Since the measure of vegetative coverage is very important in analysing the environmental degradation. Such vegetative region is measured by various vegetation index (VI) of which Normalised Differential Vegetation Index (NDVI) is used. It is a normalised band ratio of Near-Infrared (NIR) and Red (R) (Rouse et al. 1973). For Landsat OLI imagery selected bands are Band 5 (NIR) and Band 4 (RED), it can be expressed as following equation 1 :

$$
N D V I=\frac{N I R-R E D}{N I R+R E D}
$$

3.2.3 NDBI: To map the built-up, woodland, farmland, barren and water areas following index were used (Zha et al., 2003; Sharma et al., 2013) equation 2.

$$
N D B I=\frac{(S W I R 2-N I R)}{(S W I R 2+N I R)}
$$

3.2.4 EVI: The EVI was chosen over other indices due to its resistance to atmospheric noise (Matsushita, et.al. 2007). The values of the EVI range from -1 to +1 , measuring greenness over an area. The closer the values are to +1 , more the presence of vegetation. The equation 3 used to calculate the EVI as equation 3:

$$
E V I=2.5 * \frac{\left(\rho_{\text {NIR }}-\rho_{\text {RED }}\right)}{\rho_{\text {NIR }}+6^{*} \rho_{\text {RED }}-7.5 * \rho_{\text {Blue }}+1}
$$

where, $\rho=$ atmospherically corrected surface reflectance for the blue, red and near infrared bands.

3.2.5 NDWI: It is one of the band ratio techniques to extract water features. Normalised Difference Water Index (NDWI) is a normalised band ratio of Green and Near Infrared (NIR) (Wu et al, 2009; Jackson, 2004). To extract the water features from Landsat 8 data band 3 (GREEN) and Band 6 (NIR) were used and expressed as equation 4 :

$$
N D W I=\frac{(G-N I R)}{(G+N I R)}
$$

3.2.6 LST: Every process on the lithosphere, hydrosphere and biosphere are related to the LST (Voogt and Oke, 2003; Pu et al. 2006). Following expressions are popular to estimate the Land surface temperature (Chander et al., 2009; Valor and Caselles, 1996; Sobrino et al., 2004; Artis and Carnahan, 1982).

It involves 5 steps as follows: 


$$
\begin{aligned}
& \text { 1. } \begin{array}{c}
\text { Digital Numbers to spectral radiance } \\
L \lambda=M L * Q c a l+A L
\end{array} \\
& \text { 2. } \quad \begin{array}{l}
\text { Spectral radiance to brightness temperature } \\
B T=K 2 / \ln (k 1 / L \lambda+1)-273.15
\end{array} \\
& \text { 3. } \quad \text { Proportion of Vegetation } \\
& \quad P V=\left\{\frac{N D V I-N D V I_{\min }}{N I R_{\max }-N D V I_{\min }}\right\} \\
& \text { 4. } \quad \text { Land Surface Emissivity } \\
& \text { 5SE }=0.004 * P V+0.986 \\
& \text { LST } \quad \text { Land Surface Temperature } \\
& \text { (BT / } 1)+W *(B T / 1.4380) * \ln (L S E)
\end{aligned}
$$

\subsection{Multi Criteria Decision}

To evaluate the indicators and its criteria's assigning weightage and ranking is important; MCDM based two popular methods i.e. entropy and CORPAS were adopted for the study. It assign the weights based on two important components i.e. 1) alternatives and 2) criteria's. There are two types of criteria's such as benefit criteria (Maximum desire) and cost / non-benefit criteria (Minimum desire). In this study alternatives are environmental degradation class (VHD, HD, etc.) and major indicator (TI, HMI, EI, and SEI) and sub factors (slope, NDVI, LST, Population density, etc.) are the criteria's.

3.3.1 Entropy: The entropy weight function is based on the discrete probability distribution, it’s expressed as eq.6:

$$
e_{j}=\frac{-1}{\ln (m)} \sum_{i=j}^{m} n_{i j} \ln \left(n_{i j}\right)
$$

The degree of diversity (d) possessed by each criterion is evaluated as eq.7:

$$
d_{j}=1-e_{i j}, j=1,2,3
$$

The weight objective for each criterion is expressed in eq.8

$$
w_{j}=\frac{d_{i}}{\sum_{i=1}^{n} d_{i}}
$$

3.3.2 COPRAS: allows for both benefit and cost criteria to be considered within the matrix and the data are normalized so that different measurement units can be used and compared. Step 1: In the MCD problem the weights for the criterions are expresses (Johnson, 2002) as eq. 9 and eq.10

$$
\begin{gathered}
D=\left[\begin{array}{cccc}
x_{11} & x_{12} & \cdots & x_{1 n} \\
x_{21} & x_{22} & \cdots & x_{2 n} \\
\vdots & \vdots & \ddots & \vdots \\
x_{21} & x_{m 2} & \cdots & x_{m n}
\end{array}\right] \\
w_{j}=\left[w_{1} \ldots w_{n}\right], \text { where } \sum_{i=1}^{n}\left[w_{1} \ldots w_{n}\right]=1
\end{gathered}
$$

Step 2: Normalize the decision matrix by using eq 11 and the weighted normalized matrix is calculated as eq. 12

$$
\begin{aligned}
& n_{i j}=\frac{x_{i j}}{\sum_{i=1}^{n} x_{i}} \\
& N_{i j}=w_{j}^{*} n_{i j}
\end{aligned}
$$

where xij is the value of the $i$ th criterion of the $j$ th alternative, and $q i$ is the weight of the $i$ th criterion.

Step 3: To calculate the sum of the benefit criteria values $(\mathrm{Bi})$ and Calculate the sum of the cost criteria values $\left(C_{i}\right)$ eq. $13 \& 14$

$$
\begin{aligned}
& B_{i}=\sum_{j=1}^{k} N_{i j} \\
& C_{i}=\sum_{j=k+1}^{m} N_{i j}
\end{aligned}
$$

Step 4: compute the relative significance of each alternatives (Qi) eq.15:

$$
Q_{i}=B_{i}+\frac{\min \left(C_{i}\right) * \sum_{i=1}^{n} C_{i}}{C_{i} * \sum_{i=1}^{n} x_{i}\left(\frac{\min \left(C_{i}\right)}{C_{i}}\right)}
$$

Step 5: determine the utility degree for each alternatives as eq.16

$$
U_{i}=\frac{Q_{i}}{\max \left(Q_{i}\right)} * 100 \%
$$

\section{RESULTS AND DISCUSSION}

\subsection{Results}

In this study, utilisation of different remote sensing data products in GEE platform were performed and prepared all the twelve thematic layers under four groups of indicator and its spatial distribution shown in (Figure 2 and 3).

4.1.1 Assigning Factor Score: Assessment of environmental degradation successful extraction of all the thematic layers from GEE; each layers were classified into benefit and non-benefit criteria's (table 1).Then normalised the weight (Appendix 1a) to find the best score for the individual criterion shown in table 3.

\begin{tabular}{lllrrrrr}
\hline Criteria & & & \multicolumn{7}{c}{ Alternatives } \\
\hline Slope & Z & Unit & VHD & HD & MD & SD & ND \\
Aspect & - & \% & 5 & 10 & 15 & 25 & 33 \\
Elevation & - & Degree & 75 & 150 & 225 & 300 & 360 \\
NDVI & - & Ratio & 500 & 1000 & 1500 & 2000 & 2500 \\
NDBI & + & Ratio & 1 & 0.2 & 0.4 & 0.6 & 0.8 \\
LULC & + & Point & 9 & 7 & 3 & 1 & 2 \\
EVI & + & Ratio & 0.6 & 0.8 & 0.95 & 0.3 & 1 \\
RF & - & Mm & 300 & 600 & 900 & 1200 & 1500 \\
NDWI & - & Ratio & 0.2 & 0.4 & 0.6 & 0.8 & 1 \\
LST & + & Ratio & 35 & 30 & 25 & 20 & 15 \\
POPDEn & + & Per/Sqkm & 10000 & 5000 & 1000 & 500 & 100 \\
RoadPrx & - & Km & 1 & 5 & 10 & 15 & 25 \\
\hline The sign(+/-) indicates that a greater/lesser criterion value & & & &
\end{tabular}

Table1. Selected Criteria and its Alternatives

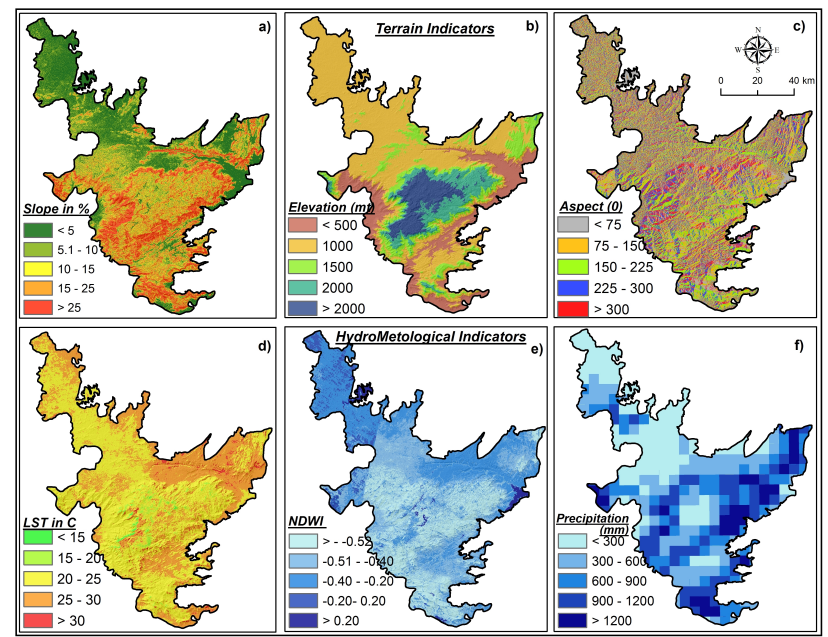

Figure 2. Thematic layers of TI and HMI 


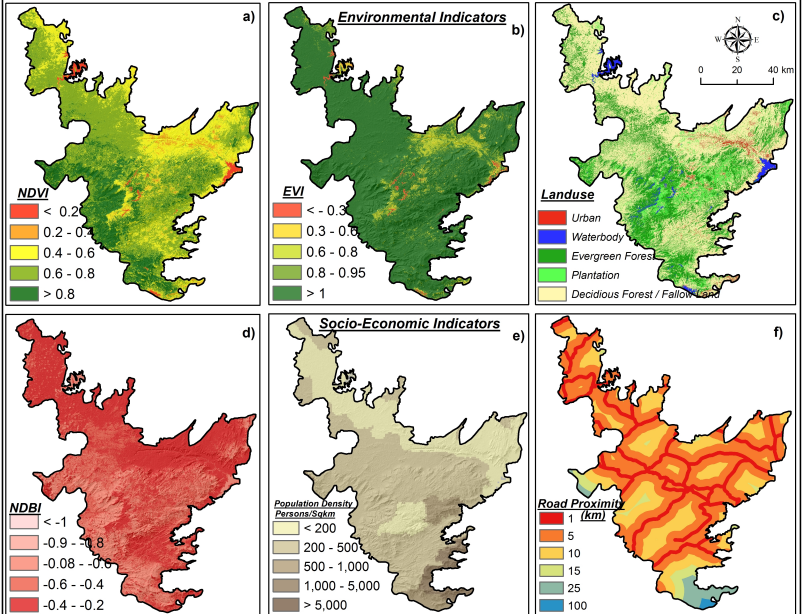

Figure 3. Thematic layers of EI and SEI

\begin{tabular}{|c|c|l|c|}
\hline $\begin{array}{c}\text { Main } \\
\text { Indicators }\end{array}$ & $\begin{array}{c}\text { MI - } \\
\text { Weight }\end{array}$ & $\begin{array}{c}\text { Sub } \\
\text { Criterions }\end{array}$ & $\begin{array}{c}\text { SBC- } \\
\text { Weight }\end{array}$ \\
\hline \multirow{3}{*}{$\begin{array}{c}\text { Topographic } \\
\text { Indicator }\end{array}$} & \multirow{2}{*}{0.26} & Slope & 0.082 \\
\cline { 3 - 4 } & & Aspect & 0.078 \\
\cline { 3 - 4 } $\begin{array}{c}\text { Environmental } \\
\text { Indicator }\end{array}$ & \multirow{2}{*}{0.31} & Elevation & 0.078 \\
\cline { 3 - 4 } & & NDVI & 0.084 \\
\cline { 3 - 4 } & & LULC & 0.078 \\
\cline { 3 - 4 } $\begin{array}{c}\text { Hydro- } \\
\text { Meteorological } \\
\text { Indicator }\end{array}$ & \multirow{2}{*}{0.29} & EVI & 0.088 \\
\hline \multirow{2}{*}{$\begin{array}{c}\text { Socio-Economic } \\
\text { Indicator }\end{array}$} & \multirow{2}{*}{0.14} & NDWI & 0.074 \\
\cline { 3 - 4 } & & LST & 0.078 \\
\cline { 3 - 4 } & POPDEn & 0.078 \\
\hline
\end{tabular}

Table 2. Main indicator and sub criterions weight

4.1.2 Terrain Indicator: Terrain is the basic element and underlying factor in all parts of scientific research analysis and that to in calculating environmental degradation. Which includes elevation, slope and aspect each of it has its own relation with that of indicating terrain characteristics. However, Slope and elevation are the major significant factors which are interrelated with each other and have positive relationship whereas aspect poses the negative relation with the terrain characteristic. The northern tip of study area is associated with high degree of degradation (Figure 4a) because of lower elevation of below $500 \mathrm{~m}$ and lower degree of slope $5 \%$. Only the central part has low degradation due to its higher elevation of $>2000$ meter and higher degree of slope 25\%. Entire north western portion with one third of the study area comes under the high degradation. Moderate level of degradation is splitted and scattered throughout the region. The high-altitude portion is in the central part which has low exposure towards degradation.

4.1.3 Environmental Indicator: The Environmental factor is considered to be the core analysis in evaluating the degradation affecting the existing environmental condition. Which include sub-factor like (Normalized Difference Vegetation Index (NDVI); Enhanced Vegetation Index (EVI), Normalized Difference Water Index (NDWI), Normalized Difference Built-up Index (NDBI); and Landuse. The NDVI and EVI are the two indices which shows the greenness and canopy cover of the forest area (Figure 3.a,b,c). The degree of depletion in a region based on its landuse pattern like barren and fallow land. Landuse map prepared from Random forest classifier, with an accuracy of 0.88 .
The positive values of NDWI, which represents the availability of water, similarly there will be possibility of degradation due to human habitation. In the view of environmental indicator, the degree of degradation is low comparing others. Here the NDVI, EVI, shows a positive range of vegetation cover almost $25 \%$ of area covered in Evergreen Forest and 50\% of area in deciduous forest, which seems to the area of two third parts in under good condition of vegetation. The Figure (4c) represents a spatial distribution of environmental indicator, the smaller region in eastern and north-western part in high degraded condition, then region in eastern part hold a moderate level of degradation. In the study area almost $75 \%$ of area is under low level of degradation.

4.1.4 Hydro-Meteorological Indicator: The progressive proportion of Hydro-Meteorological component has a vital role in indicating the damages in the ecosystem influencing degradation. Precipitation and Land Surface Temperature (LST) are the two parameters taken into account. These two are inversely proportional to each other indicating that the land surface with high temperature will comparatively receive less precipitation than that of the portion with low temperature. Almost the whole area poses average temperature between 15$25^{\circ} \mathrm{C}$. Here the central elevated and southern portion shows the less effect of degradation as this portion poses higher degree of precipitation with less proportion of land surface temperature and the entire north western stretch is affected with high degree of degradation (Figure 4b).

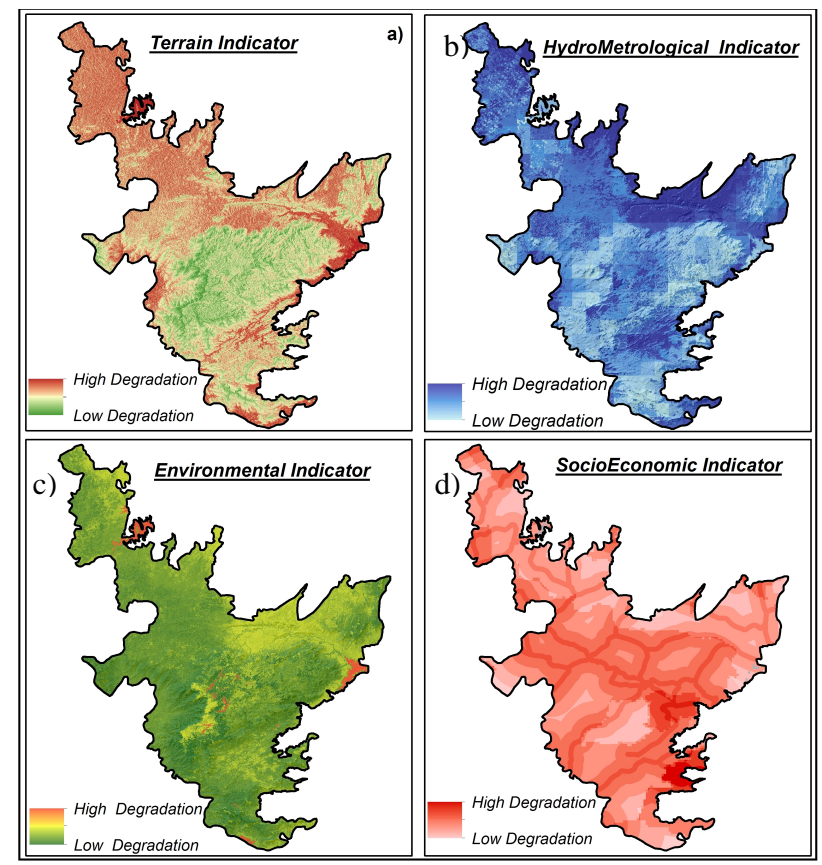

Figure 4. Degradation in each indicator

4.1.5 Socio-Economic Indicator: The utmost gratification of the analysis is achieved through the Socio-Economic factor which directly links the current position of the population endangered towards the environmental degradation. Evidently the Mudhumalai sanctuaries, Bandhipur tiger reserve are indirectly inviting people through tourism thus affecting the reserved forest regions. In this Population density and road network are chosen for screening the Socio-Economic condition. In the Road network analysis only, major roads were taken in consideration. It is a known fact that the population density will be higher in the place where the mobility with higher network of roads and subsequently in this area elevated 
region poses the adoptable climatic circumstances and provided with Evergreen Forest making it more populated. Notably, closest places near to the road within 1-5 km surrounding are highly degraded as the anthropogenic activity is high. It is clearly indicating that the central portion is highly degraded as it is with higher amount of urban population with complex network of roads. The moderate and less degraded areas (Figure 4d) are sparsely distributed mainly due to the sparse distribution of road networks.

\subsection{Discussion}

4.2.1 Environmental Degradation: The essence of Environmental degradation is derived through the subsequent indicators of Terrain, Hydro-Meteorological, Environmental and Socio-Economic elements. The figure 5 displays the spatial distribution of the degradation in the Nilgiri Biosphere Reserve with the fine classification of five classes as Very high, High, Moderate, Slight and No Degradation. The hierarchical significance of the indicators as followed to extract the Environmental Degradation were Environmental, HydroMeteorological followed by Terrain and Socio-Economic factors. Environmental indicator is given higher preference as it has the direct combined influence on the dented ecosystem effects contributing towards the degradation and the HydroMeteorological indicator is the main reason for the causes that lead to the environmental damages. Consequently, the terrain has the adverse effect on the environment as is indirectly paying sources for the grievances. Socio-Economic indicator which signifies a domination of anthropogenic influence on degradation. The whole stretch in the top of north eastern part and the tip of the north western part are showing very high degradation level covering $19.4 \%$ due to the lower altitude and supplemented by the human activity aiding towards the environmental assassination. Some section of area in the high elevated region fall under high degradation level measures $16.5 \%$ where the range of population density is high and the cultural activities like resource exploration are mending degradation. Moderate degradation prevails major part of study site occupying about $32.8 \%$ is seen in the top of middle western portion as the area poses the plateau region with average level of land surface temperature and precipitation. The $23.6 \%$ of slight degradation is mostly located in the high altitude areas with lower cultural activities. The region of no degradation covers $7.7 \%$ and is mostly seen in the high altitude region more than $2000 \mathrm{~m}$ probably seems to be evergreen forest and with the high range of rainfall between 900-1200 followed by lower temperature level $\left(<20^{\circ} \mathrm{C}\right)$.

Generally, the entire Nilgiri Biosphere has been categorised into three zones as core zone, buffer zone and transition zone for understanding the level of degradation. In the core zone, some region is highlighted as high risk, where the activities like economical deforestation and mining are common. The buffer zone is connectivity region, the most of human invasion are prolonging in the rim of the core zone, which replicates that the core is started degrading from outward. On the other hand, in the core zone the degradation happening from the mid. The transition zone is the outermost area of the biosphere where all the activities like plantation, forestry, agriculture, cropping and economic activities will tend to happen. Due to an abnormal level of degradation, the possibility of natural recovery is unreliable in this zone. Figure 5. a) Moyar-Bhavani shere zone, b) Mukarathi national park c) Attappadi RF, d) Nagarhole.

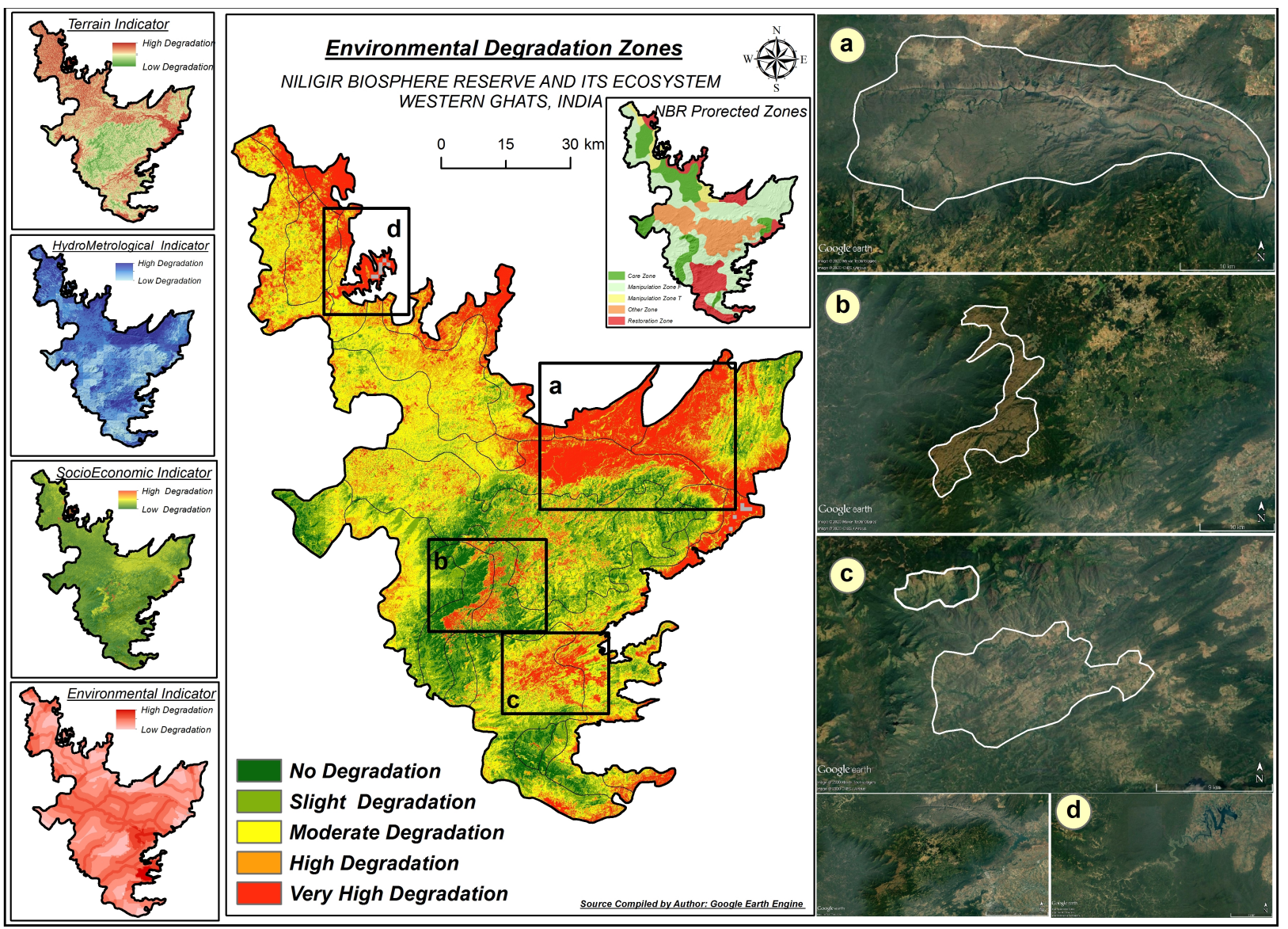

Figure 5. Distribution of Environmental Degradation Zones 


\section{CONCLUSION}

This study encompasses on determining the environmental degradation for which a framework is adopted that performs the most advanced technology in recent times for obtaining the appropriate results. Accordingly, cloud computing technology of Google Earth Engine (GEE) on one side and Entropy Techniques on the other side have been determined in computing the environmental degradation composed of elements like Terrain Indicator, Environmental Indicator, Hydro-Meteorological Indicator and Socio-Economic Indicator. Relatively machine learning Random Forest Classifiers in refining the better classification of result. The acute condition of Nilgiri Biosphere on exhaustion of ecosystem have been properly monitored for defining the twelve parameters and the framework adopted for the study have been perfectly coordinated resulting in obtaining accurate findings. The result interprets that the very high and high degradation are seen in the plateau and plain of low lying regions where the ecological damages is interrupted; needs to be shown concern for the improvement of the biosphere reserve and so as to prevent the high altitude low degraded region from environmental degradation. In the final map, even though four hotspot zone have been marked as an important protected region, they are also facing a hazardous condition. Those areas need to be protected in order to maintain the equilibrium state in biodiversity. In the demarcated biosphere both the buffer and transition zone are known for tourism activity that is EcoTourism by Tiger reserves and Elephant sanctuary which is causing human induced environmental degradation. It clearly depicts that even though the reserve forest is heavily protected it also undergo increasing degradation due to this process. From this study four hotspot zones were highlighted in order to implement the immediate response and many other conservation management and to strengthen the forest protection policies must be adapted to demarcated areas to optimize the effect of degradation.

\section{ACKNOWLEDGEMENTS}

We are very grateful to open source data, GEE Java API code provider and their timely support. Authors, thank to anonymous reviewers for their valuable suggestion. Our sincere gratitude to faculty members Department of Geography, Bharathidasan University, Tiruchirappalli, Tamil Nadu, India. SA \& RV express sincere thanks to ISPRS TIF for the necessary support.

\section{REFERENCES}

Adriaenssens, V., De Baets, B., Goethals, L. M. P., De Pauwa, N., 2004: Fuzzy rule-based models for decision support in ecosystem management. Science Total Environment., 319, 1-12, https://doi.org/10.1016/S0048-9697(03)00433-9.

BalaSundareshwaran, A., Abdul Rahaman, S., Balasubramani, K., Kumaraswamy, K., \& Ramkumar, M. (2019). Habitat Risk Assessment Along Coastal Tamil Nadu, India-An Integrated Methodology for Mitigating Coastal Hazards. Coastal Zone Management, 515-542. https://doi.org/10.1016/b978-0-12-814350-6.00023-9

Center for International Earth Science Information Network (CIESIN)/Columbia University, and Information Technology Outreach Services (ITOS)/University of Georgia. (2013). Global Roads Open Access Data Set, Version 1 (gROADSv1). Palisades, NY: NASA Socioeconomic Data and Applications Center (SEDAC). Downloaded from http://sedac.ciesin.columbia.edu/data/set/groads-global-roadsopen-access-v1.

Choudhary, K., Boori, M. S., \& Kupriyanov, A. (2018). Spatial modelling for natural and environmental vulnerability through remote sensing and GIS in Astrakhan, Russia. Egyptian Journal of Remote Sensing and Space Science, 21(2), 139-147. https://doi.org/10.1016/j.ejrs.2017.05.003

Feoli, E., Vuerich, L. G., \& Zerihun, W. (2002). Evaluation of environmental degradation in northern Ethiopia using GIS to integrate vegetation, geomorphological, erosion and socio-economic factors. Agriculture, Ecosystems and Environment, 91(1-3), 313-325. https://doi.org/10.1016/S0167-8809(01)00236-5

Funk, C., Peterson, P., Landsfeld, M. et al. The climate hazards infrared precipitation with stations-a new environmental record for monitoring $\begin{array}{lllll}\text { extremes. } & \text { Sci } & \text { Data } & 2, & \end{array}$ https://doi.org/10.1038/sdata.2015.66

Guebas, F, D., 2002: The Use of Remote Sensing and GIS in the Sustainable Management of Tropical Coastal Ecosystems. Environment, Development and Sustainability. 4, 93-112.

Google Earth Engine. (2012). Retrieved February 5, 2014, from https://earthengine.google.org/\#intro.

Hadeel, A. S., Jabbar, M. T., \& Chen, X. (2011). Remote sensing and GIS application in the detection of environmental degradation indicators. Geo-Spatial Information Science, 14(1), 39-47. https://doi.org/10.1007/s11806-011-0441-z

Hadeel, A. S., Jabbar, M. T., \& Chen, X. (2011). Remote sensing and GIS application in the detection of environmental degradation indicators. Geo-Spatial Information Science, 14(1), 39-47. https://doi.org/10.1007/s11806-011-0441-z

Hassan, M. S., Mahmud-Ul-Islam, S., \& Rahman, M. T. (2015). Integration of Remote Sensing and GIS to Assess Vulnerability of Environmental Degradation in North-Western Bangladesh. Journal of Geographic Information System, 07(05), 494-505. https://doi.org/10.4236/jgis.2015.75040

Husnayaen, Rimba, A. B., Osawa, T., Parwata, I. N. S., As-syakur, A. R., Kasim, F., \& Astarini, I. A. (2018). Physical assessment of coastal vulnerability under enhanced land subsidence in Semarang, Indonesia, using multi-sensor satellite data. Advances in Space Research, 61(8), 2159-2179. https://doi.org/10.1016/j.asr.2018.01.026

Jiang, L., Huang, X., Wang, F., Liu, Y., \& An, P. (2018). Method for evaluating ecological vulnerability under climate change based on remote sensing: A case study. Ecological Indicators, 85(2), 479-486. https://doi.org/10.1016/j.ecolind.2017.10.044

Johnson MP (2002). Decision support for family relocation decisions under the section 8 housing assistance program using GIS and the analytic hierarchy process. Journal of Housing Research; 12:277-306.

Johansen, K., Phinn, S., \& Taylor, M. (2015). Mapping woody vegetation clearing in Queensland, Australia from Landsat imagery using the Google Earth Engine. Remote Sensing Applications: Society and Environment, 1, 36-49. https://doi.org/10.1016/j.rsase.2015.06.002

Jackson, T.J., Chen, D., Cosh, M., Li, F., Anderson, M., Walthall, C., Doriaswamya, P., Hunt, E.R., 2004: Vegetation water content mapping using Landsat data derived normalized difference water index for corn and soybeans. Remote Sensing of Environment., 92, 475-482. https://doi.org/10.1016/j.rse.2003.10.021.

MacMillan, R.A., Jones, R.K., McNabb, D.H., 2004: Defining a hierarchy of spatial entities for environmental analysis and modeling using digital elevation models (DEMs). Computers, Environment and Urban Systems., 28, 175-200. https://doi.org/10.1016/S01989715(03)00019-X.

Moazami, S., Golian, S., Kavianpour, M. R., \& Hong, Y. (2013). Comparison of PERSIANN and V7 TRMM multi-satellite precipitation analysis (TMPA) products with rain gauge data over Iran. International Journal of Remote Sensing, 34(22), 8156-8171. https://doi.org/10.1080/01431161.2013.833360

Matsushita, B., Yang, W., Chen, J., Onda, Y., \& Qiu, G. (2007) Sensitivity of the enhanced vegetation index (EVI) and normalized difference vegetation index (NDVI) to topographic effects: A case study in high density cypress forest. Sensors, 7, 2636-2651.

Nesbitt, S. W., Gochis, D. J., \& Lang, T. J. (2008). The diurnal cycle of clouds and precipitation along the Sierra Madre Occidental observed during NAME-2004: Implications for warm season precipitation 
estimation in complex terrain. Journal of Hydrometeorology, 9(4), 728743. https://doi.org/10.1175/2008JHM939.1

Nitheshnirmal, S., Thilagaraj, P., Abdul Rahaman, S., Jegankumar, R., 2019: Erosion risk assessment through morphometric indices for prioritisation of Arjuna watershed using ALOS-PALSAR DEM. Modeling Earth Systems and Environment 5:1-18. https://doi.org/10.1007/s40808-019-00578-y.

Nitheshnirmal, S., Rahaman, S. A., Balasundareshwaran, A., Nivedita Priyadarshini, K., Balasubramani, K., Kumaraswamy, K. 2018: SpatioTemporal Analysis of Natural Human Habitability Environment along the Coastal Taluks of Tamil Nadu, India, ISPRS Annals Photogrammetry Remote Sensing. Spatial Inf. Sci., IV-5, 439-446, https://doi.org/10.5194/isprs-annals-IV-5-439-2018.

Nanki Sidhu, Edzer Pebesma \& Gilberto Câmara (2018) Using Google Earth Engine to detect land cover change: Singapore as a use case, European Journal of Remote Sensing, 51:1, 486-500, https://doi.org/10.1080/22797254.2018.1451782

Othman, A. A., Al-Saady, Y. I., Al-Khafaji, A. K., \& Gloaguen, R. (2014). Environmental change detection in the central part of Iraq using remote sensing data and GIS. Arabian Journal of Geosciences, 7(3), 1017-1028. https://doi.org/10.1007/s12517-013-0870-0

Rahaman, S. A., Aruchamy, S., Jegankumar, R., Ajeez, S. A.2015: Prioritization of Sub Watershed Based on Morphometric Characteristics Using Fuzzy Analytical Hierarchy Process and Geographical Information System - A Study of Kallar Watershed, Tamil Nadu. International conference on water resources, coastal and ocean engineering (icwrcoe 2015). Aquatic Procedia 4:1322 -1330. https://doi.org/10.1016/j.aqpro.2015.02.172.

Rouse, J., Haas, R., Well, J., \& Deering, D. (1973). Monitoring Vegetation Systems in the Great plains with ERTS. Third ERTS-1 Symposium, 309-317.

Rigina, O., 2002: Environmental Impact Assessment of the Mining and Concentration Activities in the Kola Peninsula, Russia by Multidate Remote Sensing. Environmental Monitoring and Assessment., 75, 1333. https://doi.org/10.1023/A:1014248522919.

Sahoo, S., Dhar, A., \& Kar, A. (2016). Environmental vulnerability assessment using Grey Analytic Hierarchy Process based model. Environmental Impact Assessment Review, 56, 145-154. https://doi.org/10.1016/j.eiar.2015.10.002

Store, R., Jokima“ki, J., 2003: A GIS-based multi-scale approach to habitat suitability modeling. Ecological Modelling., 169, 1-15. https://doi.org/10.1016/S0304-3800(03)00203-5.

Teluguntla, P., Thenkabail, P., Oliphant, A., Xiong, J., Gumma, M. K., Congalton, R. G., Yadav, K., \& Huete, A. (2018). A 30-m landsatderived cropland extent product of Australia and China using random forest machine learning algorithm on Google Earth Engine cloud computing platform. ISPRS Journal of Photogrammetry and Remote Sensing, 144, 325-340. https://doi.org/10.1016/j.isprsjprs.2018.07.017

Voogt, J., \& Oke, T. (2003). Thermal remote sensing of urban climates. Remote Sensing of Environment, 86, pp. 370-384.

Vogt, J., Safriel, U., Von Maltitz, G., Sokona, Y., Zougmore, R., Bastin, G., Hill, J., (2011). Monitoring and assessment of land degradation and desertification: towards new conceptual and integrated approaches. Land Degrad. Dev. 22, 150-165.

Wang, X. D., Zhong, X. H., Liu, S. Z., Liu, J. G., Wang, Z. Y., \& Li, M. H. (2008). Regional assessment of environmental vulnerability in the Tibetan Plateau: Development and application of a new method. Journal of Arid Environments, 72(10), 1929-1939. https://doi.org/10.1016/j.jaridenv.2008.06.005

Wu, C., Niu, Z., Tang, Q., Huang.W., 2009: Predicting vegetation water content in wheat using normalized difference water indices derived from ground measurements. Journal of Plant Research.,122, 317-326, https://doi.org/10.1007/s10265-009-0215-y.

Zhao, J., Ji, G., Tian, Y., Chen, Y., \& Wang, Z. (2018). Environmental vulnerability assessment for mainland China based on entropy method. $\begin{array}{llll}\text { Ecological } & \text { Indicators, } & \text { 91(April), } & \text { 410-422. }\end{array}$ https://doi.org/10.1016/j.ecolind.2018.04.016
Zurqani, H. A., Post, C. J., Mikhailova, E. A., Schlautman, M. A., \& Sharp, J. L. (2018). Geospatial analysis of land use change in the Savannah River Basin using Google Earth Engine. International Journal of Applied Earth Observation and Geoinformation, 69(December 2017), 175-185. https://doi.org/10.1016/j.jag.2017.12.006.

\section{APPENDIX}

Appendix 1: Normalised Criterion weight of benefit (green) and non-benefit (Red) values for environmental degradation and significances of the alternatives

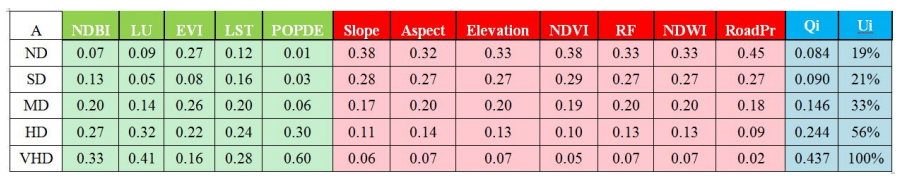

Appendix 2: The snapshots of Google Earth Engine Platform and its generated various results. Landuse and its accuracy assessment, LST, NDBI Shows in bellow images.

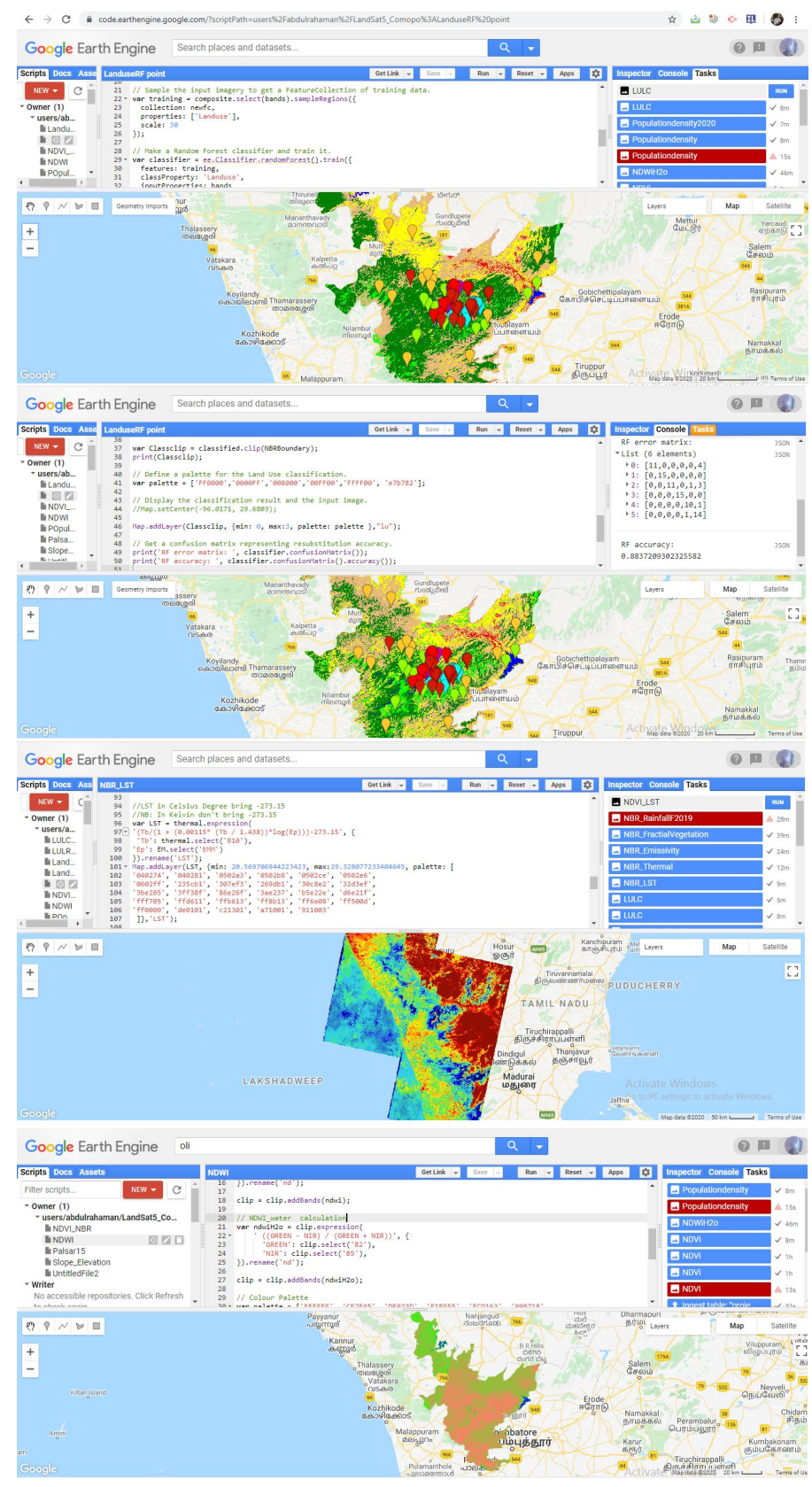

